[Article]

\title{
金属粉末的吸氢统计热力学模型
}

\author{
吴广新 $1,2,3,{ }^{*}$ 彭望君 ${ }^{1,2,3}$ 张捷宇 ${ }^{1,2,3}$ \\ ( ${ }^{1}$ 上海大学, 高品质特殊钢治金与制备国家重点实验室, 上海 $200072 ;{ }^{2}$ 上海大学, 上海钢铁冶金新技术重点实验室, \\ 上海 200072; ${ }^{3}$ 上海大学, 材料科学与工程学院, 上海 200072)
}

\begin{abstract}
摘要: 提出了一种基于零阶 Bragg-Williams 近似的新统计热力学模型。新模型的独特之处在于引入了表观 压缩系数 $\alpha$ 来校正高压气体的体积变化, 并且在拟合结果中获得无环状曲线。然后, 新模型成功应用于金 属粉末的吸氢过程。所有结果表明这个新模型运行很好, 特别是新模型可用于预测不同温度下的 PCT 曲线。 因此，我们的新模型可以在实际系统中应用。
\end{abstract}

关键词: 统计热力学理论; 氢化过程; 储氢材料粉末

中图分类号: 0642

\section{Statistic Thermodynamic Model of Hydrogen Absorption on Metal Powders}

\author{
WU Guang-Xin ${ }^{1,2,3,{ }^{*} \quad \text { PENG Wang-Jun }}{ }^{1,2,3} \quad$ ZHANG Jie-Yu ${ }^{1,2,3}$ \\ ( ${ }^{1}$ State Key Laboratory of Advanced Special Steels, Shanghai University, Shanghai 200072, P. R. China; ${ }^{2}$ Shanghai Key \\ Laboratory of Advanced Ferrometallurgy, Shanghai University, Shanghai 200072, P. R. China; ${ }^{3}$ Department of Materials Science \\ and Engineering, Shanghai University, Shanghai 200072, P. R. China)
}

\begin{abstract}
Based on zero-order Bragg-Williams approximation, a new statistic thermodynamic model is presented herein. The distinctive feature of the new model is that an apparent compressibility factor $\alpha$ is introduced to correct the volume change of high-pressure gases and ensure no loop-like curves are obtained in the fitting results. The new model is successfully applied to investigate hydrogen absorption on metal powders. Our results indicate that the model works very well and can be used to predict PCT curves at different temperatures. Hence, our new model exhibits significant potential for application in practical systems.
\end{abstract}

Key Words: Statistic thermodynamic theory; Hydriding process; Hydrogen storage materials powder

\section{Introduction}

In the analysis of data on the absorption isotherm, it is useful to have an analytic representation of phase quilibria (Pressure-Composition-Temperature, PCT diagram) to optimize the specific application of hydrogen by metals or intermetallic powder. The first model for describing the PCT curves was proposed by Lacher ${ }^{1}$ in 1937 for the Pd-H system because Pd is able to absorb a lot of hydrogen. And mathematical expressions were obtained based on the interstitial site occupation to fit isothermal curves of the logarithm of hydrogen gas pressure as a function of the hydrogen concentration in the metal powder. However, Lacher-type isotherm describes a simplified ideal rather than real behaviour of metal-hydrogen systems. To extend this work, several researchers, such as Beeri et $a l^{2,3}$,

Received: December 9, 2016; Revised: February 28, 2017; Published online: March 22, 2017.

${ }^{*}$ Corresponding author. Email: gxwu@shu.edu.cn; Tel/Fax: +86-21-56337920.

The project was supported by the National Natural Science Foundation of China $(51104098,51674163)$ and Science and Technology Committee of Shanghai, China (14521100603, 16ZR1412000).

国家自然科学基金(51104098, 51674163)和上海科学技术委员会(14521100603, 16ZR1412000)资助

(C) Editorial office of Acta Physico-Chimica Sinica 
Lexcellent et $a{ }^{4}{ }^{4}$, Fang et al..$^{5-7}$ and Lototsky et $a l . .^{8-11}$ and so on $^{12-18}$, gave more efficiency expressions to fit better these PCT experiment points. However, up to now, the loop-like curves still appear in plateau of PCT diagram.

It is well known that for the Sievert's system, the hydrogen capacity is calculated by general equation. It should be realized that when high pressures, about 4-5 MPa hydrogen pressure in real case, are involved, small errors in volume induce quite large errors in the calculated hydrogen capacity. Therefore, even minor volume changes should be considered. However, it is difficult for modified general equation, such as van der Waals $^{19}$, Berthelot and Dieterici equations, to be applied in real case due to the reason of third degree of equations. In order to obtain the thermodynamic parameters, such as enthalpy and entropy from the PCT diagram, high pressure of hydrogen gas should be substituted by fugacity concept. Although Beeri et $a l^{2}$ proposed this idea and performed it in a real case, it still appears too complex to be used in a comprehensive research fields conveniently.

In this paper, a new model of statistic thermodynamics based on Bragg-Williams approximation will be presented, which could deal with loop-like curve situation of fitting and is simple enough to be solved analytically with a personal computer. Moreover, our new model will be performed to obtain enthalpies and entropies as a function of composition in practical hydrogen storage metal powder.

\section{Derivation of formulae}

The statistical problem is to determine the distribution of hydrogen between the powder solid and gaseous phases in this chemical reaction process. The gas of the hydrogen exists mainly as molecules with a few atoms; while in the metal powder it exists mainly as protons and electrons ${ }^{1,20}$. The connection between solid and gaseous phases is the chemical potential. The hydrogen of gaseous phase could be obtained through classic thermodynamics principle while that of solid phase is more complex. The major solution is to determine the partition function of hydrogen atom which includes factors of energy and degeneracy. For the aspect of energy, it is assumed that there are several potential energy holes in the metal powder for the protons to go into. And all these holes are assumed to be equivalent and there are $N$ of them, say in a given body of metal. The energy of a hydrogen molecular dissociation to two hydrogen atoms is denoted by $X$. Two interaction energy parameters are then introduced, one, $E_{\mathrm{a}}$, associated with the energy of hydrogen-metal lattice, and the other, $\omega$, related to pairwise nearest neighbors $\mathrm{H}-\mathrm{H}$ interactions with coordinate number of $Z$. In order to obtain analytical expressions for the corresponding energy term and for the partition function of the solid, some simplified assumptions are usually made for the type of configurational distribution of the $\mathrm{H}$ atoms among the available sites. In the previous treatment of a single-site occupation, two approximations were applied, the zero-order
Bragg-Williams ${ }^{19}$ which assumes a random distribution of single $\mathrm{H}$ atoms among the available sites, and the first-order Quasi-Chemical $^{19}$ which allows for the formation of dimmer clustering. It has been proposed by Beeri et al. ${ }^{2,3}$ that no significant differences were obtained between these two approximations. Hence, only the more simple Bragg-Williams approximation will be applied in this paper and the hydrogen will be considered to fill the occupied sites randomly.

Assuming that in the M-H system, the available sites of hydrogen atoms are denoted by $N$, one obtains:

$$
N_{\mathrm{f}}+N_{v}=N
$$

where $N_{v}$ represents the corresponding void sites, $N_{\mathrm{f}}$ is occupied sites which has been filled.

The total free energy of the absorbed phase is given $b^{21}$ :

$$
E\left(N_{\mathrm{f}}\right)=-N_{\mathrm{f}} \cdot E_{\mathrm{a}}+\frac{1}{2} N_{\mathrm{f}} \cdot \chi+\frac{1}{2} N \cdot Z \cdot \omega \cdot\left[\frac{N_{\mathrm{f}}}{N}\right]^{2}
$$

where in the right formula, the first item is heat of adsorption, the second item is the dissociation energy of hydrogen molecule and the third item represents the free energy of interaction between the absorbed hydrogen atoms. And $\chi$ is the dissociation energy of hydrogen molecule and $E_{\mathrm{a}}$ is the heat of absorption at infinite dilution of site.

Taking into account the number of physically distinguishable states, we obtain the following expression for the partition function:

$$
\Omega\left(N_{\mathrm{f}}\right)=\frac{N !}{N_{\mathrm{H}} ! \cdot\left(N-N_{\mathrm{H}}\right) !} \mathrm{e}^{-\frac{E\left(N_{\mathrm{f}}\right)}{k T}}
$$

where degeneracy is treated using zero-order Bragg-Williams method $^{22}$. And equation (3) has been translated with extraction method.

The configurational part of the Helmholtz free energy of solid could be determined by

$$
\begin{aligned}
& A=-k T \ln \left[\Omega\left(N_{\mathrm{f}}\right)\right] \\
& =-k T\left\{-\frac{E\left(N_{\mathrm{f}}\right)}{k T}+\ln \left[\frac{N !}{N_{\mathrm{f}} ! \cdot\left(N-N_{\mathrm{f}}\right) !}\right]\right\} \\
& =E\left(N_{\mathrm{f}}\right)-k T \ln \left[\frac{N !}{N_{\mathrm{f}} ! \cdot\left(N-N_{\mathrm{f}}\right) !}\right] \\
& =E\left(N_{\mathrm{f}}\right)-k T\left[N \ln N-N_{\mathrm{f}} \ln \left(N_{\mathrm{f}}\right)-\left(N-N_{\mathrm{f}}\right) \ln \left(N-N_{\mathrm{f}}\right)\right]
\end{aligned}
$$

The assumption of equality of the chemical potential in gas phase $1 / 2 \mathrm{H}_{2}$ with one of the $\mathrm{H}$ in solid solution gives:

$$
\frac{1}{2} \mu\left(\mathrm{H}_{2}\right)=\mu(\mathrm{H} \text { in } \mathrm{M})
$$

is given by another analyse form:

$$
\frac{1}{2}\left[\mu^{0}\left(\mathrm{H}_{2}\right)+k T \ln f\right]=-k T\left(\frac{\partial \ln \Omega}{\partial N_{\mathrm{H}}}\right)_{N, V, T}=\frac{\partial A}{\partial N_{\mathrm{H}}}
$$

where $k$ is Boltzmann constant.

The left formula (6) is expanded $b^{3,19,23}$ :

$$
\begin{aligned}
& \mu^{0}\left(\mathrm{H}_{2}\right)=k T \times C(T)-D_{0} \\
& C(T)=7.78-3.5 \times \ln T+\ln \left[1-\exp \left(-\frac{6240}{T}\right)\right]
\end{aligned}
$$




$$
D_{0}=7.17 \times 10^{-19} \mathrm{~J} \cdot \text { molecule }^{-1}
$$

Due to the high pressure gas in experiments, the pressure is substituted by fugacity. And one obtains ${ }^{2}$ :

$$
\begin{aligned}
& \ln f=\int_{o}^{P}[Z(P, T)-1] \frac{\mathrm{d} P}{P} \\
& Z(P, T)=1+\sum_{i=1}^{m} \frac{a_{i}(T)}{V_{i}(P)}
\end{aligned}
$$

where $Z(P, T)$ represents compressibility factors, $a_{i}(T)$ is the viral coefficients and $V_{i}(P)$ is the molar volume of the gas.

Because equation ${ }^{24}$ is still too complex to be used to obtain the thermodynamics results in real case. This equation is further predigested as follow:

$$
\int_{0}^{P}[Z(P, T)-1] \frac{\mathrm{d} P}{P} \approx(\alpha-1) \ln P
$$

Then one obtains:

$$
\ln f=\alpha \ln P
$$

where $\alpha>1$.

The right of formula (6) can be expressed as:

$$
\begin{aligned}
& \frac{\partial A}{\partial N_{\mathrm{f}}}=\frac{\partial E\left(N_{\mathrm{f}}\right)}{\partial N_{\mathrm{f}}}-k T \frac{\partial \ln g}{\partial N_{\mathrm{f}}} \\
& =E_{\mathrm{b}}+\frac{1}{2} \chi+a N_{\mathrm{f}} / N+k T \ln \left(\frac{N_{\mathrm{f}}}{N-N_{\mathrm{f}}}\right)
\end{aligned}
$$

Here, we define hydrogen concentration, $\rho=\frac{N_{\mathrm{f}}}{N}$, then:

$$
\frac{\partial A}{\partial N_{\mathrm{f}}}=E_{\mathrm{b}}+\frac{1}{2} \chi+Z \omega C+k T \ln \left(\frac{C}{1-C}\right)
$$

Substituting Eqs.(11) and (13) into Eq.(6) yields:

$$
\begin{aligned}
& \ln \left(P_{\mathrm{H}_{2}}\right)=\frac{2}{\alpha k T}\left[\frac{2 E_{\mathrm{b}}+\chi+D_{0}}{2}+Z \omega \rho\right]+ \\
& \frac{2}{\alpha} \ln \left(\frac{\rho}{1-\rho}\right)-\frac{C(T)}{\alpha}
\end{aligned}
$$

Equation (14) gives a relation of the hydrogen pressure as a function of the hydrogen concentration and temperature of reaction.

\section{Discussion}

\subsection{Property of new model}

Fowler ${ }^{20}$ suggested general theory of adsorption isotherms exhibiting plateau behaviour at temperatures below critical. Then, Lacher ${ }^{1}$ modified this theory for the description of PCT diagram in $\mathrm{H}_{2}-\mathrm{Pd}$ system. Both PCT models were derived statistically using Bragg-Williams approximation of the attractive interaction between the nearest neighbours of the adsorbate species. The deviations of PCT diagrams in real metal-hydrogen systems from the modelled "ideal" behaviour so far were mainly considered as regards to sloping plateaux. Actually, in Lacher-type isotherm, loop-like curves are obtained in the plateau which is considered as phase transition between $\alpha$ and $\beta$ phases. Compared with Lacher-type isotherm, our new model is non-antisymmetry. In this case, loop-like curves would be substituted by straight lines, thus artificial error has been introduced ${ }^{1}$. Above the critical temperature, no phase transition is encountered, and a single-phase solid solution of $\mathrm{H}$ in the parent metal sublattice is maintained throughout the whole composition range of the isotherms ${ }^{2}$. However, in this paper, apparent compressibility factor $\alpha$ has been introduced to correct the volume change of high pressure gas. And no loop-like curves are obtained in the fitting results (in Fig.1). Where $C\left(\mathrm{H} / \mathrm{H}_{\max }\right)$ represents concentration of hydrogen. Hence, our new model could describe the experiments more suitable.

\subsection{Inflexion points}

In order to obtain the inflexion points after the apparent compressibility factor was introduced, we perform the mathematical analyse as follows:

$$
\begin{aligned}
& \ln \left(P_{\mathrm{H}_{2}}\right)^{\prime}=\frac{2 Z \omega}{\alpha k T}+\frac{2}{\alpha} \cdot \frac{1}{\rho(1-\rho)} \\
& \ln \left(P_{\mathrm{H}_{2}}\right)^{\prime \prime}=\frac{2}{\alpha} \cdot \frac{\rho^{2}-(1-\rho)^{2}}{\rho^{2}(1-\rho)^{2}}
\end{aligned}
$$

Here we define $\ln \left(P_{\mathrm{H}_{2}}\right)$ " and obtain $\rho=0.5$. It indicates that similar to characteristic feature of Lacher-type isotherms ${ }^{26}$, our new model still has inflexion point in midpoint of plateau.

\subsection{Apparent compressibility factor}

It must be emphasized here that, the new conception, "apparent compressibility factor" $\alpha$, is a very important and useful parameter. It can be seen from Fig. 2 that, if one makes a further simplifying assumption, $\alpha=1$, absorption isotherm is reduced to the Lacher equation. However, increasing the value of apparent compressibility factor $\alpha$, the loop-like curve in plateau tends to be a horizontal line. Therefore, in order to describe real case accurately, the appropriate value of apparent compressibility factor would be obtained by non-linear curve fitting.

\section{Application to practical systems}

\subsection{Application in $\mathrm{MgH}_{2}$ powder system}

The pressure-composition-temperature curves of $\mathrm{MgH}_{2}$ powder $^{27}$ at temperature of 543,560 and $578 \mathrm{~K}$ can be fitted with good accuracy with our new model as shown in Fig.3. The apparent compressibility factor $\alpha$ is calculated with a value of 3.96.

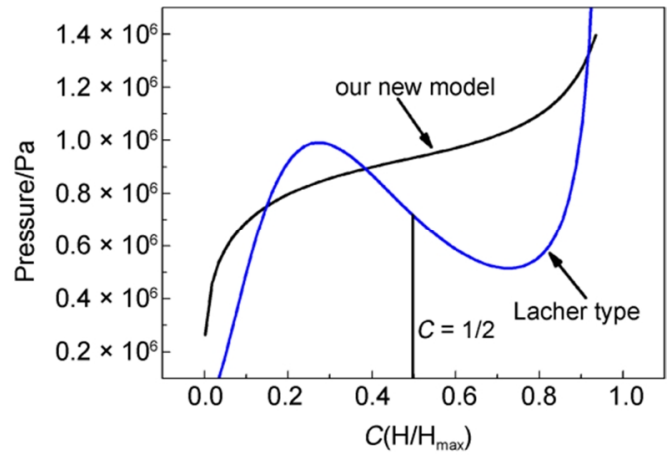

Fig.1 Schematic illumination of our new PCT model and Lacher-type model 


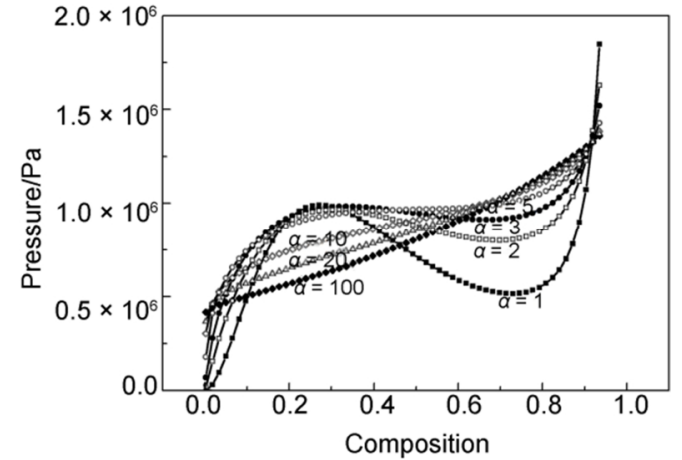

Fig.2 Our PCT function plots at various $\alpha$ values

With the value of $\alpha$ increasing from 1 to 100 , it can be seen that the shape of the curves change from S-type to linear-type.

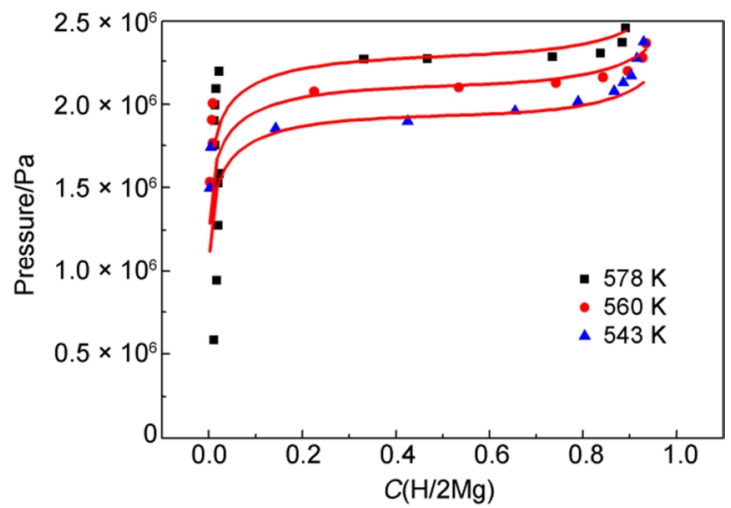

Fig.3 Comparison between the experimental (points) and the fitted (solid lines) isotherms

All pressure values were corrected to fugacities. Then, according the results of fitting, we obtain the data of $1 / T$ versus different compositions as shown in Table 1 and Fig.4.

Next, using the data of slope and intercept of each line, we can obtain the enthalpies and entropies of different composition as shown in Table 2. Then, the data in Table 2 will be fitted as follows (shown in Fig.5):

Finally, partial molar $\Delta H$ and $\Delta S$ as a function of $\mathrm{H} / \mathrm{M}$ composition ratio in $\mathrm{MgH}_{2}$ system could be achieved as follows:

It can be concluded that with the increasing $\mathrm{H} / \mathrm{M}$ composition ratio, the enthalpy and entropy will be enhanced. The reason is that the more complete reaction, the bigger value of enthalpy, the bigger value of entropy. Meanwhile, we notice that the experimental enthalpy and entropy of $\mathrm{MgH}_{2}$ is about $-70--81.25 \mathrm{~kJ} \cdot \mathrm{mol}^{-1}$ and $-119-144.29 \mathrm{~J} \cdot \mathrm{mol}^{-1} \cdot \mathrm{K}^{-1}{ }^{28}$,

Table 1 Data of $T^{-1}$ versus $\ln P$ for $C=0.3, C=0.5$ and

\section{$C=0.7$ fitted by the equation}

\begin{tabular}{cccc}
\hline$T^{-1} / \mathrm{K}^{-1}$ & $C=0.3$ & $C=0.5$ & $C=0.7$ \\
\hline $1 / 578$ & 2.533006 & 2.636683 & 2.731689 \\
$1 / 560$ & 2.058243 & 2.141512 & 2.229907 \\
$1 / 543$ & 1.577163 & 1.654813 & 1.726456 \\
\hline
\end{tabular}

The Van't Hoff plots 1/T versus $\ln P$ are shown in Fig.4.

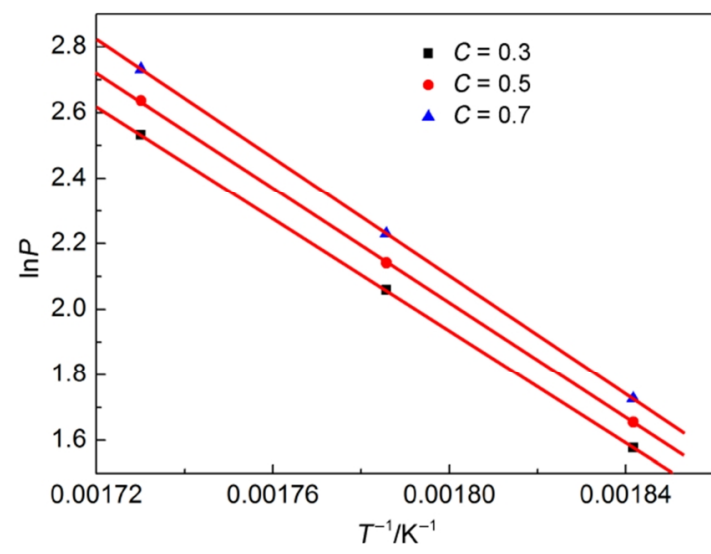

Fig.4 Van't Hoff plots for some H/M composition ratios

Table 2 Data of slope and intercept for $C=0.3$, $C=0.5$ and $C=0.7$

\begin{tabular}{ccc}
\hline $\mathrm{H} / \mathrm{Mg}$ molar ratio & $\Delta H /\left(\mathrm{kJ} \cdot \mathrm{mol}^{-1}\right)$ & $\Delta S /\left(\mathrm{J} \cdot \mathrm{mol}^{-1} \cdot \mathrm{K}^{-1}\right)$ \\
\hline 0.3 & -71.2276 & -144.262 \\
0.5 & -73.1661 & -148.48 \\
0.7 & -74.9076 & -152.297 \\
\hline \multicolumn{3}{c}{ change from S-type to linear-type }
\end{tabular}

which is in according with our results of calculation.

\subsection{Application in $\mathrm{MgH}_{2}-8 \% \mathrm{LaNi}_{0.5}$ powder system}

The pressure-composition-temperature curves of $\mathrm{MgH}_{2}-8 \%$ $\mathrm{LaNi}_{0.5}$ (molar fraction) ${ }^{29}$ at temperature of 553,563 and $573 \mathrm{~K}$ can be fitted with good accuracy with our new model as shown in Fig.6. The apparent compressibility factor $\alpha$ is calculated with a value of 1.05 .

Then, according the results of fitting, we obtain the data of $1 / T$ versus different compositions as shown in Table 3 and Fig.7. Next, using the data of slope and intercept of each line, we can obtain the enthalpies and entropies of different composition as shown in Table 4 . Then, the data in Table 4 will be fitted as follows (shown in Fig.8).

Finally, partial molar $\Delta H$ and $\Delta S$ as a function of $\mathrm{H} / \mathrm{M}$ composition ratio in $\mathrm{MgH}_{2}-8 \% \mathrm{LaNi}_{0.5}$ system could be achieved as follows:

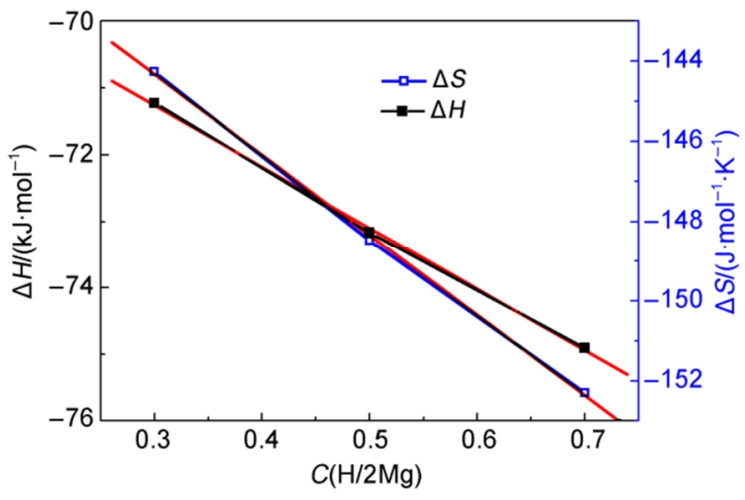

Fig.5 Partial molar $\Delta H$ and $\Delta S$ as a function of $H / M$ composition ratio 


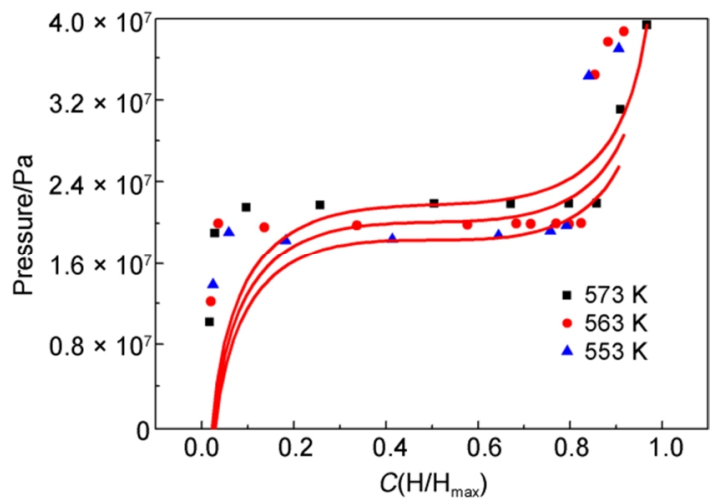

Fig.6 Comparison between the experimental (points) and the fitted (solid lines) isotherms

All pressure values were corrected to fugacities.

Table 3 Data of $T^{-1}$ versus $\ln P$ for $C=0.2, C=0.35$ and $C=0.5$ fitted by the equation

\begin{tabular}{cccc}
\hline$T^{-1} / \mathrm{K}^{-1}$ & $C=0.3$ & $C=0.5$ & $C=0.7$ \\
\hline $1 / 573$ & 0.422978 & 0.562469 & 0.702206 \\
$1 / 563$ & 0.158114 & 0.271172 & 0.401725 \\
$1 / 553$ & -0.11878 & -0.0317 & 0.061377 \\
\hline
\end{tabular}

The Van't Hoff plots $T^{-1}$ versus $\ln P$ are shown in Fig.7.

$$
\begin{array}{ll}
\Delta H=-61.65483-32.65899 \times C & \left(\mathrm{~kJ} \cdot \mathrm{mol}^{-1}\right) \\
\Delta S=-109.3434-62.88946 \times C & \left(\mathrm{~J} \cdot \mathrm{mol}^{-1} \cdot \mathrm{K}^{-1}\right)
\end{array}
$$

In order to reflect the character of plateau more appropriately, $\mathrm{H} / \mathrm{M}$ composition ratio $C=0.5$ is chosen to compare the enthalpies and entropies of pure and doped $\mathrm{MgH}_{2}$ powder system. The enthalpy and entropy for pure $\mathrm{MgH}_{2}$ powder system are $84.376--73.166 \mathrm{~kJ} \cdot \mathrm{mol}^{-1}$ and $-151.562--148.48$ $\mathrm{J} \cdot \mathrm{mol}^{-1} \cdot \mathrm{K}^{-1}$, respectively, while those for $\mathrm{MgH}_{2}-8 \% \mathrm{LaNi}_{0.5}$ powder system are $78.229--74.903 \mathrm{~kJ} \cdot \mathrm{mol}^{-1}$ and $-141.201-$ $-136.532 \mathrm{~J} \cdot \mathrm{mol}^{-1} \cdot \mathrm{K}^{-1}$, respectively. It could be concluded that catalyzer reactant could not affect the thermodynamic property of solvent, which is according with the classic thermodynamic principles. Meanwhile, all above show that our new model could be used not only in pure but also in catalyzer-doped hydrogen storage materials.

Furthermore, as shown in Fig.9, partial molar $\Delta H$ and $\Delta S$ as a function of $\mathrm{H} / \mathrm{M}$ composition ratio in both pure $\mathrm{MgH}_{2}$ and

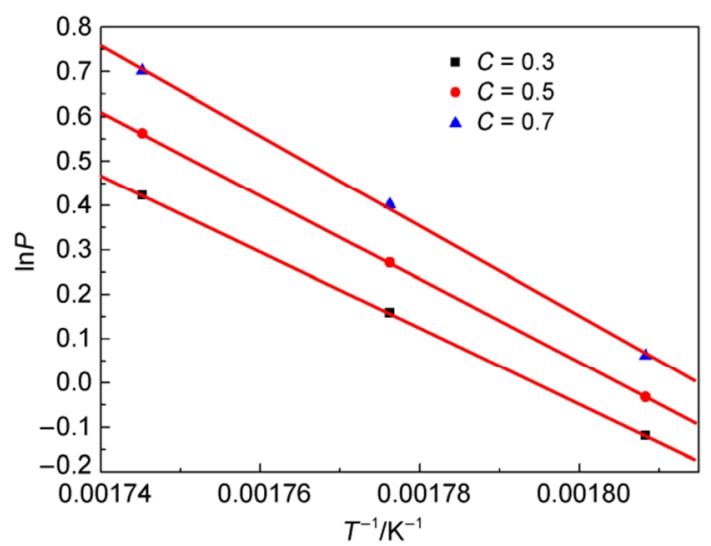

Fig.7 Van't Hoff plots for some H/M composition ratios

Table 4 Data of slope and intercept for $C=0.3$,

\begin{tabular}{ccc}
\multicolumn{3}{c}{$\boldsymbol{C}=\mathbf{0 . 5}$ and $\boldsymbol{C}=\mathbf{0 . 7}$} \\
\hline H/Mg molar ratio & $\Delta H /\left({\left.\mathrm{kJ} \cdot \mathrm{mol}^{-1}\right)} \Delta S /\left(\mathrm{J} \cdot \mathrm{mol}^{-1} \cdot \mathrm{K}^{-1}\right)\right.$ \\
\hline 0.3 & -71.3303 & -128.004 \\
0.5 & -78.2288 & -141.201 \\
0.7 & -84.3939 & -153.16 \\
\hline
\end{tabular}

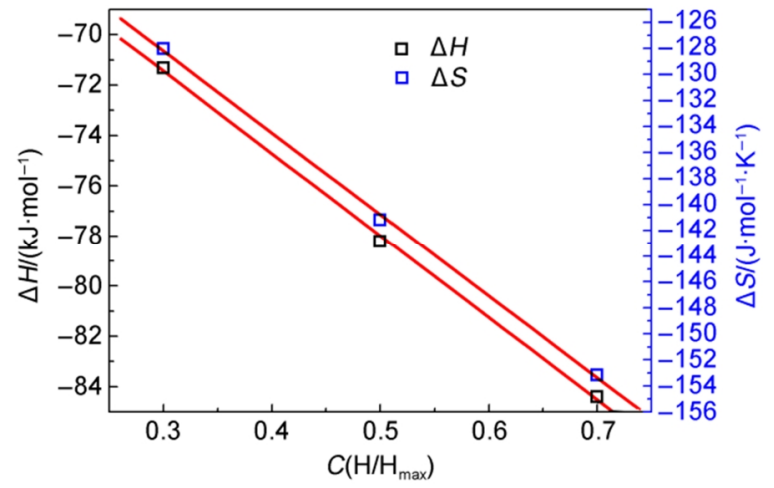

Fig.8 Partial molar $\Delta H$ and $\Delta S$ as a function of $\mathrm{H} / \mathrm{M}$ composition ratio

$\mathrm{MgH}_{2}-8 \% \mathrm{LaNi}_{0.5}$ systems could be obtained as follows:

$$
\begin{array}{ll}
\Delta H=-63.58972-27.00238 \times C & \left(\mathrm{~kJ} \cdot \mathrm{mol}^{-1}\right) \\
\Delta S=-117.22809-53.05873 \times C & \left(\mathrm{~J} \cdot \mathrm{mol}^{-1} \cdot \mathrm{K}^{-1}\right)
\end{array}
$$

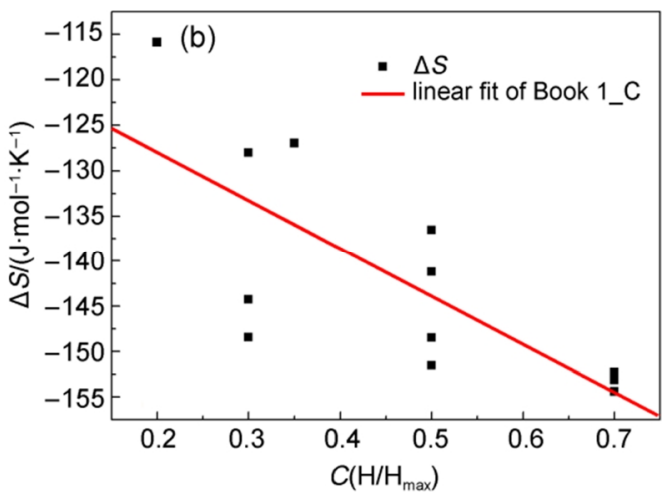

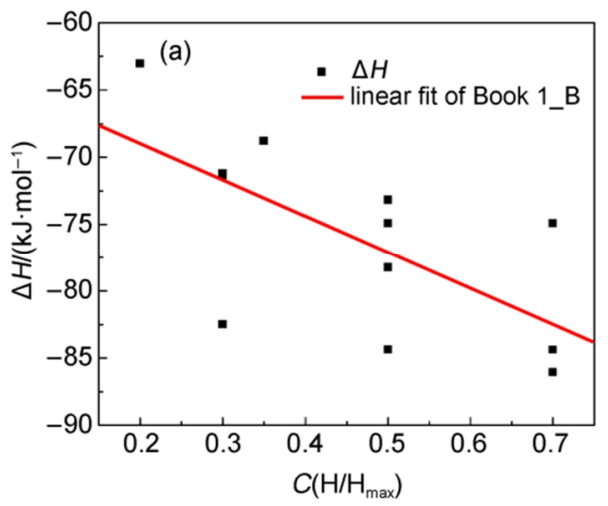

Fig.9 Partial molar $\Delta H$ and $\Delta S$ as a function of $\mathrm{H} / \mathrm{M}$ composition ratio 


\section{Conclusions}

In order to overcome the disadvantage of Lacher-type model, a new statistic thermodynamic model based on zero-order Bragg-Williams approximation has been proposed in this paper. $\ln \left(P_{\mathrm{H}_{2}}\right)=\frac{2}{\alpha k T}\left[\frac{2 E_{\mathrm{b}}+\chi+D_{0}}{2}+Z \omega \rho\right]+\frac{2}{\alpha} \ln \left(\frac{\rho}{1-\rho}\right)-\frac{C(T)}{\alpha}$

The distinct character of our new model is non-antisymmetry compared to Lacher-type model. In Lacher-type isotherm, below the critical temperature loop-like curves are obtained in the plateau and that would be substituted by straight lines, thus artificial error has been introduced. In this paper, apparent compressibility factor $\alpha$ has been introduced to correct the volume change of high pressure gas. And no loop-like curves are obtained in the fitting results. Hence, our new model could describe the experiments more suitable.

Then, the new model is successfully applied for a real case, such as pure $\mathrm{MgH}_{2}$ and $\mathrm{MgH}_{2}-8 \% \mathrm{LaNi}_{0.5}$ powder systems. Partial molar $\Delta H$ and $\Delta S$ as a function of $\mathrm{H} / \mathrm{M}$ composition ratio could be obtained as follows:

$$
\begin{aligned}
& \Delta H=-63.58972-27.00238 \times C \quad\left(\mathrm{~kJ} \cdot \mathrm{mol}^{-1}\right) \\
& \Delta S=-117.22809-53.05873 \times C \quad\left(\mathrm{~J} \cdot \mathrm{mol}^{-1} \cdot \mathrm{K}^{-1}\right)
\end{aligned}
$$

All results indicate that this new model works very well and it should be emphasized that after optimized the parameters of new model with finite temperatures, we could predict PCT curves in other temperatures. Hence, our new model could be applied in practical system significantly.

\section{References}

(1) Lacher, J. R. A Theoretical Formula for the Solubility of Hydrogen in Palladium. In Proceedings of the Royal Society of London. Series A, Mathematical and Physical Sciences (1934-1990), 1937; p 525.

(2) Beeri, O.; Cohen, D.; Gavra, Z.; Johnson, J. R.; Mintz, M. H. J. Alloy. Compd. 1998, 267, 113. doi: 10.1016/S0925-8388(97)00521-5

(3) Beeri, O.; Cohen, D.; Gavra, Z.; Mintz, M. H. J. Alloy. Compd. 2003, 352, 111. doi: 10.1016/S0925-8388(02)01155-6

(4) Lexcellent, C.; Gondor, G. Intermetallics.2007, 15, 934 doi: 10.1016/j.intermet.2006.11.002

(5) Fang, S.; Zhou, Z.; Zhang, J.; Yao, M.; Feng, F.; Northwood, D. O. J. Alloy. Compd. 1999, 293-295, 10. doi: 10.1016/S0925-8388(99)00380-1

(6) Fang, S.; Zhou, Z.; Zhang, J.; Yao, M.; Feng, F.; Northwood, D. O. Int. J. Hydrog. Energy 2000, 25, 143. doi: 10.1016/S0360-3199(99)00032-4

(7) Zhou, Z.Q.; Fang, S.S.; Feng, F. Trans. Nonferrous Met. Soc. China 2003, 13,864 .

(8) Lototsky, M.; Yartys, V.; Marinin, V.; Lototsky, N. J. Alloy. Compd. 2003, 356, 27. doi: 10.1016/S0925-8388(03)00095-1
(9) Lototskyy, M.; Yartys, V.; Pollet, B.; Bowman, R. Int. J. Hydrog. Energy 2014, 39, 5818. doi:10.1016/j.ijhydene.2014.01.158

(10) Davidson, D.; Raman, S. S.; Lototsky, M.; Srivastava, O. Int. J. Hydrog. Energy 2003, 28, 1425. doi: 10.1016/S0360-3199(02)00194-5

(11) Lototskyy, M.; Klochko, Y.; Linkov, V.; Lawrie, P.; Pollet, B. Energy Procedia 2012, 29, 347. doi: 10.1016/j.egypro.2012.09.041

(12) Jewell, L.L.; Davis, B. H. Appl. Catal. A-Gen. 2006, 310, 1. doi: 10.1016/j.apcata.2006.05.012

(13) Wagner, C. Acta Metall. 1971, 19, 843. doi: 10.1016/0001-6160(71)90140-4

(14) Kuji, T.; Oates, W.; Bowerman, B.; Flanagan, T. J. Phys. F: Metal. Phys. 1983, 13, 1785. doi: 0305-4608/13/9/007

(15) Chabane, D.; Harel, F.; Djerdir, A.; Candusso, D.; Elkedim, O.; Fenineche, N. Int. J. Hydrog. Energy 2016, 41, 11682. doi: 10.1016/j.ijhydene.2015.12.048

(16) Oates, W.; Flanagan, T.B. J. Mater. Sci. 1981, 16, 3235. doi: $10.1007 / \mathrm{BF} 00586283$

(17) Young, K.; Ouchi, T.; Fetcenko, M. J. Alloy. Compd. 2009, 480, 440. doi: 10.1016/j.jallcom.2009.03.194

(18) Payá, J.; Linder, M.; Laurien, E.; Corberán, J. J. Alloy. Compd. 2009, 484, 190. doi: 10.1016/j.jallcom.2009.05.069

(19) Hill, T. L. An Introduction to Statistical Thermodynamics; Dover Publications: New York, 1986.

(20) Fowler, R. H.; Guggenheim, E. A. Statistical Thermodynamics of Super-Lattices, Proceedings of the Royal Society of London. Series A, Mathematical and Physical Sciences (1934-1990), 1940; Vol. 174, 189.

(21) Tanaka, T.; Keita, M.; Azofeifa, D. E. Phys. Rev. B 1981, 24, 1771 doi: 10.1103/PhysRevB.24.1771

(22) Bragg, W. L.; Williams, E. J. The Effect of Thermal Agitation on Atomic Arrangement in Alloys, In Proceedings of the Royal Society of London. Series A, 1934; p 699.

(23) Fukai, Y. The Metal-Hydrogen System; Springer-Verlag: Berlin, Heidelberg, 1993.

(24) Lototskyy, M. Int. J. Hydrog. Energy 2016, 41, 2739. doi: 10.1016/j.ijhydene.2015.12.055

(25) Saita, I.; Toshima, T.; Tanda, S.; Akiyama, T. J. Alloy. Compd. 2007, 446-447, 80. doi: 10.1016/j.jallcom.2007.04.020

(26) Zeng, K.; Klassen, T.; Oelerich, W.; Bormann, R. Int. J. Hydrog. Energy 1999, 24, 989. doi: 10.1016/S0360-3199(98)00132-3

(27) Li, Q.; Chou, K. C.; Xu, K. D.; Lu, X. G.; Zhang, J. Y.; Lin, Q.; Jiang, L. J. J. Mater. Sci. Eng: A 2007, 457, 1. doi: 10.1016/j.msea.2007.01.120 